\title{
Talent Acquisition a Key Factor to Overcome New Age Challenges and Opportunities for Human Resource Management
}

\author{
Mr. Shyamasundar Tripathy \\ Management Faculty (PG Dept.) Institute of Professional Studies and Research, Cuttack, Odisha, India
}

\begin{abstract}
One of the most surprising outcomes of the 2007-2009 recessions is that talent acquisition particularly top talent - is actually harder, not easier, than before the downturn. Despite the fact many wellrespected, out-of-work executives are clamoring to get back in the game, surveys show companies are failing to find the right talent to fill reinstated positions. In a recent study by the Corporate Leadership Council, 72 percent of companies predict they will have a large number of leadership vacancies over the next three to five years. Even more surprising, 76 percent said they are "less than confident" in their abilities to adequately staff these positions. This phenomenon is worldwide. The chief executive of global recruitment agency Manpower recently told the World Economic Forum that 30 percent of companies across the globe continue to struggle to fill available positions. Global searches confirm the increased difficulty getting candidate's attention. The situation is pervasive and clearly a result of a miserable economy, high unemployment and a rampant sense of anxiety and insecurity among the well-employed executives. The "Dot Com" era was tough but this is an even tougher time! There are several reasons why companies are struggling to fill their empty positions. In addition to the impact of retiring Baby-Boomer executives and the lack of qualified replacements ready to assume strategic positions and the role of HR department also more important to overcome this talent gap in the organization
\end{abstract}

Key words: Downturn, Reinstated positions, 'Dot Com" era, Baby-Boomer executives, Talent gap

\section{Introduction}

A strategic approach to identify, attract and onboard top talent into the organization, the Talent Acquisition process has evolved a lot in the past decade. As the business gets more dynamic \& complex and talent becomes short in supply, what will differentiate the leader from the rest of the pack will be their ability to draw top talent. The talent hunting will focus on how companies are redrawing their talent strategies in the new HRD era

This paper aim to create a platform for discussion around innovations in talent acquisition in the context of the present agile and global workforce. It will showcase new practices that have evolved to cope with the new and changing talent sourcing challenges as it effectively contributes to business strategy.

\section{Objective}

- To exchange new-age practices in talent acquisition - methods and new learning on what the best in the industry are doing to meet their talent challenges.

- Additionally sensitize Talent and HR Managers on the challenges and opportunities in the talent market to optimize it as a business driver.

- A focused and differentiating approach towards talent acquisition and its subsequent management is critical for continuous business growth.

- To focuses on the trends and best practices in the recruitment function and will be beneficial for HR heads, Recruitment, TA and HR professionals across industries.

\section{The New Talent Acquisition Edges}

Remember when HR was referred to as the personnel department? It was non-strategic and highly tactical - little more than hiring employees, administering benefits, tracking attendance and handling employee issues. Today HR is a considered a core business function and talent acquisition was referred to as the recruiting department - with no more responsibility than reviewing resumes, screening candidates, and organizing candidate interviews. The phrase "talent acquisition" is now mainstream - and is embraced by both large and small organizations. Companies understand that there is a broad end-to-end focus needed; one which stretches from building a strategic employment brand, through sourcing and recruiting, all the way to on boarding top people. Recruitment is an essential element of talent acquisition (and includes sourcing, selecting, hiring and on boarding), but it is one of many processes that fall under this highly complex talent area, including: 
- Planning and Strategizing

- Segmenting the Workforce

- Creating, Validating and Maintaining an Employment Brand

- Delineating Candidate Audiences

- Managing and Cultivating Candidate Relationships

- Defining Metrics and Conducting Analysis

- Creating an Organizational Recruiting Culture

Within each of these core elements of talent acquisition are many other sub-activities and best practices. And, of course, the selection of tools, technology and outsourcing partners is a key element of a company's talent acquisition strategy. Best-practice organizations are focusing on strategic areas (such as employment branding, social networking, candidate relationship management and key analytics) and have tightly integrated talent acquisition with talent management - organizationally, systemically and technologically.

\section{Strategies Tool For New Age Talent Acquisition}

Now each organization focused on finding, developing and keeping highly talented people in their teams and organizations excel above the competition. Effective leaders know that a key competitive differentiator today is in innovative, critical thinking, prudent risk-taking, and ambitious talent. The constant ebb and flow of the current economic tide makes it is increasingly important for leaders to identify retain and advance top talent to ensure they have the right people, at the right time in the right positions. In other words, that there is alignment between leadership, business strategy, talent development and succession planning.

Here are six strategies you can employ to gain a talent advantage.

\section{Create a charismatic culture that pulls in highly skilled and talented people}

Nothing attracts top talent to an organization like top talent. That is an immutable organizational fact. There is a charismatic culture that attracts extraordinary talent and it starts with leaders. While running a small organization never left the hiring, managing or promoting of talent to anyone else. This is a key responsibility in building the best team in the marketplace and built the company brand and company people brand to such a positive level that the company was very attractive to top talent, to the extent of having the pick of the crop. Top talent is attracted to strong corporate brands but in the end it's the people they work with who are the ultimate magnets.

\section{Build a sticky culture that adheres extraordinary talent}

Top talent wants to be challenged and recognized (some desire public accolades others prefer private rewards.) Ensure that your organization offers emerging leaders challenges and exceptional learning opportunities for professional and personal growth. Review training programs for relevance and create fulfilling experiences for top talent by engaging in a regular dialogue to evaluate their level of engagement. Would you describe your culture as a glue stick, epoxy or crazy glue?

\section{Build a Social-Media framework for talent acquisition}

Social media doesn't need to be the absolute center of your recruitment strategy, but it would be illadvised to ignore the trend completely. Factors like personal, transparent, social marketing and more sharing are changing and advancing the ways of approach finding the best talent and taking it to a more personal, open and collaborative experience. Employees on Twitter, LinkedIn, and Facebook are contributing to the efforts of recruiting through their own posts and tweets. Not only are open positions getting distributed as pieces of content to vast networks of people, but it's also facilitating the use of social referrals - one of the best sources of quality candidates. Job seekers are finding ways to take advantage of social referrals by keeping in contact and engaging with key members of companies.

\section{Implement rising stars as a goodwill builders for referral program}

The brightest and the best people know others just like them. Some of the most talented team members sourced came from referrals from existing staff. If you do step one and two above with aplomb the referrals will naturally come. To expedite the process, you can make it formal by communicating to your top talent that you are looking for similar folks and reward them in some fashion for bringing good people to the table. No amount of advertising can compete with rising star word-of-mouth. 
Talent Acquisition a Key Factor to Overcome New Age Challenges and Opportunities for ...

\section{Communicate your organization's career development programs}

Don't keep your robust career growth opportunities a secret. It never ceases to amaze me how many talented folks in organizations are unaware of the plethora of programs and policies available to them. Oftentimes, these are terrific attraction, retention and advancement tools that go unnoticed and unused. Use all your communication channels - website, company bulletin boards, and intranet, and employee handbook, newsletters - to optimize awareness of your talent development opportunities internally and externally.

\section{Annually assess top performers for future potential}

As Marshall Goldsmith has eloquently said: "What got you're here won't get you there." It is important not to confuse high performance with high potential. The high performance moniker is often bestowed as a result of an employee's contribution in a current role; this is no guarantee of future potential. In fact, recent research suggests that more than $70 \%$ of today's top performers are not high potentials. They may have what it takes now to succeed, but are missing the integral attributes required for future roles.

\section{Implement Talent Acquisition Strategies To Meet Business Need}

When companies complain that they can't find enough good people, the cause, in our view, is most likely to be deep-rooted and centered on a misalignment between the strategic goals of the business and the efforts of the company's talent acquisition professionals. Long term business plans must be flexible - they need to change when the circumstances that gave rise to them change. If there is a fundamental change in direction or focus, everything else must be reviewed and where necessary adapted or even redesigned to reflect the change. Too often, the talent acquisition plan gets overlooked, or cannot flex quickly enough, and the result is the business begins to fall behind competitors in the 'war for talent. Designing the talent acquisition strategy is a critical first step in allowing leaders in the HR function to get that crucial alignment. These are the key, seven steps we followed and can be used as a template for your own efforts:

1. Look at the key skills required to ensure business objectives are continuously met, and regularly review them.

As the pharmaceutical industry evolves so do the skills required within any business. Companies work in a variety of therapy areas which often change, therefore the required specific therapy expertise can also vary. You don't want to be hiring 'key' people only to see their expertise become redundant within a matter of months.

\section{Do a skills gap analysis to show where you are exposed.}

As the business portfolio evolves there is often a need to bring new skills, techniques or areas of expertise into the organization. Identifying those gaps early is vital. It helps HR professionals map the market to determine where that talent currently sits, how big a potential candidate pool there is and where the potential obstacles might arise, e.g. location.

\section{Develop an internal mobility and succession plan to ensure good people are being utilised optimally.}

Having a succession plan in place is a crucial component to any company's workforce plan. It not only acts as a great motivator with existing key people but also acts as a retention tool.

\section{Plan for attrition.}

Again, this is a very important element in workforce analytics for presenting to business leaders. By forecasting future leavers it helps leaders plan accordingly for any skills gaps and back-fill appropriately, and in good time.

\section{Analyze company demographics to ensure diversity objectives are met.}

Diversity is no longer optional. It has become absolutely essential within any business as, in our opinion, it drives creativity and innovation. From gender to ethnicity, it is important to get the balance right. One of the biggest problems in almost all industries is that women in senior leadership roles remain rare. At Pfizer, although we always chose the best person for the job, we made a concerted effort to ensure diverse candidate short lists were always provided to hiring teams.

\section{Determine gaps and therefore external recruitment needs.}

Once the internal skills have been identified and succession planning has been implemented, any clear gaps can be determined; what's going to be critical in the near future and what's needed for the longer term. 


\section{Define and develop an external sourcing strategy.}

Strategies and tactics used to recruit active jobseekers are quite different to those used for 'passive candidates'. These are people who are currently quite happy where they are working but might be open to the idea of a move - if it's the right one, proposed and presented well. In the past, when companies were operating in a comparatively 'steady state', a big corporate brand was often enough to produce a good candidate roster. Today, corporate brands have a limited shelf life and should not be over-relied on. Only a compelling, personalized and value-led employment proposition will attract the best people.

\section{Talent Acquisition Intricacy}

\section{It's harder to identify talent - to separate the wheat from the shaft.}

With so many talented executives sidelined during the recession, one would think it would be easy to post an ad and bring in a plethora of good candidates. Not so. In fact, the task of identifying the right talent for open positions has become more and more daunting. It's a little like looking for the proverbial needle in the haystack. If you want to find that unique individual with the perfect experience, background and management style to fill your position, you better have strong market intelligence and a compelling story to tell candidates. Your recruiters must know everything about the position and come from a place of credibility. The "gates" are more heavily guarded now than ever before as candidates have their guards up and are less motivated to think about moving.

\section{It takes twice as much effort to attract the right candidate.}

After recession the qualified candidates are more cynical and skeptical - and afraid. Therefore they are harder to attract and entice. For example, if a prime candidate is currently employed, it may take you twice as long to get his or her attention, let alone convince him or her to walk away from a secure gig to look at your opportunity. Most employed executives are keeping their heads down and their noses to the grindstone. Candidates believe venturing into the great unknown in a volatile market makes far less sense then staying in a familiar surprise-free job.

\section{It takes more creativity and flexibility to land the necessary talent.}

Now companies with open positions do not have the upper hand in the negotiating part of the executive search game. Wages are starting to spike up again as competitive companies begin looking for similar talent. What's more, if prospects feel poorly treated or short-changed on compensation and benefits packages, and consequently walk away from the opportunity, the company's reputation can take a hit in the marketplace. This will make hiring good talent now as well as in the future harder and harder. The ability of individuals to share their negative reactions via Twitter, Facebook, eBoss, BadCompany and other social media should give companies enough reason to create positive experiences with every potential candidate, even those they know they don't want to hire from the onset.

\section{People are redefining and reposition their experience}

In order to compete in the race and be attractive to more companies. What they are doing, in many cases, is recreating and repositioning their history to be more generally applicable to a broader range of job specifications. As hiring companies get more focused on finding the right fit for their new strategic plan or toplevel replacement, individuals are presenting their backgrounds with broader and more general strokes. This compounds the problem of matchmaking.

Technology revolution: All of a sudden, everyone is a "digital expert"

Talking about cloud computing and content - terms one should really never use because of their ambiguity. So sifting through well-written "marketing collateral," - the new term for "resume" - takes more time, a keen eye and, ultimately, a face-to-face meeting to sort fiction from reality.

\section{Talent \& Performance Management}

Talent Development Strategies develops integrated talent reviews, succession planning and other talent management initiatives that drive business results and are critical to business strategy. So a comprehensive performance management programs ideally required to meet company's objectives and create a highperformance culture. Finally, a rigorous promotion processes to help identify the cadre of leaders with the potential to succeed into more senior roles within the company.

Talent Assessment and Review -focus on business-related talent challenges, identify key talent and implement key development initiatives to retain them.

Succession Planning -identify critical jobs and successors to fill those jobs and assume key leadership positions within your firm.

Talent Development -retain key talent by focusing on specific development activities for your employees.

Performance Management Process - develop an efficient, yet rigorous performance management process that fits your business strategy to achieve key goals. 
Performance Appraisals - create specific job-related competencies and performance appraisals tailored to jobs in your organization.

Performance Management Coaching - provide customized coaching to help leaders have effective performance discussions with direct reports.

Promotion Process - develop and implement comprehensive promotion processes to ensure that the right people are selected for the next level of leadership.

\section{Conclusion}

Thoughtful organizations and leaders build strategy around acquiring talent to meet both current and future business needs. Before adding staff or simply filling a vacant position, it is important to have clear sense of the "gaps" as they relate to the skill sets needed to meet current and future performance requirements. Otherwise, you are simply adding people that may or may not contribute to the organization's success. Once a gap analysis has been conducted and managers have a good sense of their staffing needs including the availability of talent, they are in a position to execute on a plan to acquire the needed skills and talent. Often organizations will use more than one method (e.g. recruiting, sourcing, training \& development).Whether acquiring outside talent or developing talent from within the organization, ideally, managers should be building a network or "hot file" of candidates to draw from when the need arises. Recruiting and sourcing can certainly be outsourced to staffing \& recruitment agencies, allowing businesses to focus more time on core competencies. With that said, good managers assume accountability for actively growing and developing their own people - regardless of whether they use outside services to recruit or source candidates. The new talent paradigm requires the dynamic integration of HR and diversity strategy to optimize and unleash the creativity and innovation of a diverse and talented workforce..A clear business case for integrated HR/diversity efforts has not been articulated. While experts understand the need new talent paradigm calls for an active link between HR and diversity in articulating the need of business.

\section{Journal Papers}

[1]. Bersin by Deloitte .. “ Talent Management Framework” In 2006

[2]. Finders Keepers: "Five Strategies to Attract and Retain Extraordinary Talent" By: Lisa Martin, Lisa Martin International

[3]. An Oracle White Paper June 2012 "The Future of Talent Management: Four Stages of Evolution"

[4]. SHRM: Improving Talent Management Strategies, 2/22/2013

\section{Books}

[5]. Lance A. Berger and Dorothy R. Berger: The Talent Management Handbook page- 3-10

[6]. Ryan Estis: "Trends in Talent Management" page- 8-14

[7]. McKinsey: "Talent management strategy" page- 168-172

[8]. The Future of Talent Management: Four Stages of Evolution page-115-116

\section{Proceedings Papers:}

[9]. Sajjad Masud: 5 Ways Social Media Is Revolutionizing Talent Acquisition

[10]. Suzi Alligood \& Gina Todd: The Talent Challenge

[11]. Tom Bradley and Christian Steele: Design and implement talent acquisition strategies to meet corporate goals

[12]. Barry Shulman: Talent acquisition is surprisingly harder in this new era

[13]. Amy Van Ditti Xenium: Training for Talent - Manage, Motivate and Measure

[14]. Thought Leadership :The New Talent Management Paradigm Thought Leadership

[15]. Edna Chun and Alvin Evans : Integrating HR and Diversity Strategy 